\title{
The Diverse Patterns and the Diverse Causes of Migration and Mobility in Science
}

\author{
ULRICH TEICHLER and ALESSANDRO CAVALLI \\ International Centre for Higher Education Research, INCHER-Kassel, University \\ of Kassel, Moenchebergstr. 17, 34109 Kassel, Germany. E-mail: teichler@incher. \\ uni-kassel.de
}

Five major themes are often addressed in the discourse of mobility in science: the definition and classification of the persons in mind (scholars, academics, researchers, etc); the frequency and the configuration of mobility; the roles mobility and migration play for the individuals; the roles they play for institutions (universities, research institutes, enterprises, etc); and finally the relevance of mobility and migration for the overall international activities within higher education and research in a 'globalized world'. This article summarizes the concepts and findings presented as regards these themes in all of the articles in this special issue of European Review. The discourse both on concepts and findings suggests that mobility and migration are often viewed in isolation rather than in a wider context of features of internationalization. Moreover, attention often focuses on mobility and migration at the apex of the prestige and quality pyramid, notably in the countries most strongly involved; differences by country, sector and position in the reputational hierarchy would be viewed as more relevant if European policies aimed at a balance between market developments and cohesion across Europe and for keeping inequalities between European countries within limits.

\section{Introduction}

Both the public discourse as well as the research undertaken on mobility (and possibly migration) in science address five major themes. These themes have been discussed, in one way or another, in the preceding articles, and the variety of ways these themes have been handled will be reflected upon here.

First, there is the identification, clarification, delineation, classification, and so on, of the issue under consideration: who do we have in mind (scholars, academics, 
researchers, etc)? Do we include, for example in statistical analyses or in surveys, persons who are not predominantly scholars or researchers (i.e. contracts for individual projects, persons spending only one or a few hours per week on research, etc)? Do we set limits according to educational attainment (all persons active in higher education and R\&D or only persons with a certain degree or professional definition, persons with any degree or only persons with a doctoral degree)? Do we focus on the university sector, or do we take into account all higher education, or even all tertiary education? Do we define R\&D according to institutional information or on the basis of labour force survey descriptions of professional functions? What stages of the formation of research competences do we include (do we exclude initial degree stages or even the stage of work on doctoral dissertation, and do we consider doctoral candidates as students or young researchers)? Are we solely interested in migration and mobility during the course of professional work as scholars or in any life stage? Do we want to pay attention to distinct separate types and modes of mobility and migration or to the overall, cumulative pattern of moves over time? What are the thresholds of time and purposes: is even the attendance of a conference included or a stay abroad for a language course? The classifications undertaken might even go beyond such more or less descriptive categories and employ interpretative categories such as 'migration' vs. 'mobility', 'horizontal' vs. 'vertical' mobility, 'brain drain' and 'brain gain' as well as 'brain circulation', etc. Also, the decision about whether attention is paid to citizenship ('foreign' scholars or scholars being 'abroad') or to mobility between locations (e.g. research work in a country different from that of education prior to enrolment in higher education, prior domicile, etc), as a rule, is not merely based on operational convenience, but rather on conceptual or political rationales.

Second, there is the frequency as well as the configuration ('patterns' or the 'map') of mobility (migration, and so on). In this framework, we also observe an implicit or explicit methodological debate. For example, do we pay attention to absolute figures and report that the US hosts more scholars than any other country and more Chinese study or work on dissertation abroad than citizens of any other country? Or do we examine mobility rates, e.g. percentages of all scholars or of the whole population, and note that the US hosts fewer scholars and that China sent fewer persons abroad than the average of economically advanced countries? This is also relevant for the analysis of cooperation and mobility in science within Europe: when reference is made to absolute figures, the United Kingdom, Germany and France are often named as hosting countries, coordinators of research, etc, but when reference is made to relative figures, countries such as Sweden, Switzerland, the Netherlands, etc, are often taken into consideration. Moreover, we note that the reports on 'facts' are often driven more strongly by the availability of data than by the stated purpose of analysis. In spite of the shortcomings of many data sources and presentations, a substantial range of revealing information is available - notably, if one does not only consult official statistics, but also takes representative surveys and other similar sources into consideration. Thus, we can see, for example, as will be discussed below, that growth trends are impressive according to some features of mobility but less impressive according to others, that short encounters in other countries grow more than long-term mobility and migration, and that events and accumulations over career spans or over the 
whole life-span deserve more attention than incidences of mobility at a certain moment in time, which in the past had been in the limelight of discussions.

Third, there are the roles mobility and migration play for the individuals: who actually is mobile? How much does mobility differ by socio-biographic background? What motives drive mobility? What is the impact of mobility on academic and research careers and the actual scholarly work and its results and, overall, how small or impressive is such an impact of mobility? To what extent do causes for mobility and the impact of mobility vary according to the modes, the lengths, the stages in life, and so on, of mobility? What contextual factors stimulate mobility or turn out to be barriers? What policies seem to support or constrain mobility?

Fourth, there are the effects mobility and migration have on institutional settings at the meso-level (i.e. for individual institutions of higher education, research institutes and enterprises as well as for aggregates of institutions, e.g. types of higher education institutions or sectors of industry), as well as at the macro-level (i.e. for individual countries or for geographic, geo-political and economic groups, e.g. the European Union, the European Bologna signatory countries, or the economically advanced countries - e.g. members of OECD). Actually, the majority of presentations at the international conference, which led to this collection of articles, as well as the subsequent discussions, focused on the macro-level thematic area, which is currently in the limelight, i.e. how countries (and possibly supra-national regions) fare as regards mobility compared to others, what that means for their technological advancement, economic growth and societal well-being, and what policies do they pursue or should they pursue to counteract presumed weaknesses. These analyses tend to be tainted by different value judgements as regards cooperation, market-like competition or domination vs. sub-ordination or even tones close to knowledge 'wars' and they tend to take for granted that high rates of mobility are most desirable.

Fifth, there is the relevance of mobility and migration within the overall patterns of international activities in higher education and research, as well as within higher education and research in a 'globalized world'. Whereas some analyses and discourses focus on mobility and migration, thereby implicitly or explicitly depicting it as the most relevant aspect of internationality (mostly named 'internationalization', which takes a growth trend for granted), others see it as one of various aspects beside international cooperation in research processes and co-publishing through various means, an emphasis on international and global dimensions in research and teaching, the establishment of branch institutions and programmes in other countries, international knowledge transfer through various means, or any type of virtual internationalization and globalization. One might ask whether mobility and migration are likely to grow along with other means of transfer or whether they will be substituted gradually by other means. And one might ask as well, which means will be the most efficient and the most effective ones in the long run.

\section{Definitions and Classifications}

Critique is often voiced that information on student mobility is poor and that information on the mobility of scholars is even poorer. The paucity of information seems 
to be in obvious contrast to the relevance attributed in the public discourse to mobility in this sphere for the overall future of the knowledge system in a globalized society.

A closer look, however, reveals that the critique seldom addresses merely the paucity of data as such. Rather, three aspects tend to be criticized or missed, which are not in the domain of facts and figures, but rather in the conceptual and classificatory domain.

First, we note divergent views as regards the definitions and the appropriate inclusion or exclusion of phenomena. For example, there is a gap between the definitions and delineations in the statistics controlled by the appropriate educational sector regarding national and international agencies in charge of data collection, which collects information on students and 'teachers' in tertiary education on the one hand, and on the other those controlled by the science and technology sector, which collects information on researchers. This does not only hold true for the types of scholars to be included and excluded, but also for the handling of phases of learning vs. productive work, or for the minimum of professional involvement (employee status, minimum hours on research work per week, etc) taken into consideration. Often, reports on mobility and migration present figures without classificatory information - whether they refer to researchers or staff in research units or whether they cover higher education or tertiary education; the reader of such data does not know whether statistics refer to scholars or include support staff for research and those teachers in tertiary education who are workers without any tertiary education qualifications.

Second, the lack of data is often due to a lack of dynamism of statistical data collection. For example, most statistical data collections on scholars still focus on citizenship, i.e. 'foreign' and 'abroad'; this might be viewed as a 'cultural lag'. The more mobile a society becomes, the less foreign citizenship is a clear indicator of mobility. More information is needed on mobility in terms of border-crossing. Additionally, while some decades ago, attention focused on student mobility for the whole study programme or mobility for the whole dissertation phase and statistical emphasis on 'degree mobility' was appropriate, short-term mobility - for a semester or a year or some period within the work on dissertation - in the meantime has become a frequent phenomenon and a darling of governmental and supra-national policies in Europe; but short-term mobility still is excluded or at least neglected in official international statistics. Moreover, we became aware in recent years of the relevance of various relatively small mobility activities that were not addressed in traditional data collections. For example, some analyses of professional mobility comprise 'commuters' and 'overnighters'; as regards scholars and researchers, short visits certainly have become a relevant phenomenon.

Third, there is a widespread disappointment that available statistical information on mobility and migration often has only limited explanatory power for the key issues under consideration - for example for the roles that mobility and migration play for the individuals, institutions and countries and for the weight physical mobility has in the overall processes of internationalization and globalization in science. One would like to use data as 'indicators' and to have 'evidence' as a basis for policy decisions, 
but the available quantitative information often does not allow such a targeted use, because it remains open for a broad range of interpretations.

However, the articles in this issue, focusing on the state of information on mobility and migration in science, demonstrate not only the limits and gaps of some sources, but they also summarize information that is more detailed and more relevant for the key issues under consideration than the official statistics. They show the results of studies that have been drawn from various sources, and they provide overviews of the findings of major comparative representative questionnaire surveys. Certainly, questionnaire surveys have typical weaknesses, such as possible biased and uncontrolled differences between the respondents and non-respondents as well as findings shaped by the ways the questions have been posed, but they move substantial steps forward in showing the trajectories of mobility in the life course, the motives for being mobile or being not mobile, as well as the impact of mobility on careers and work in the world of science.

\section{Quantities and Patterns of Mobility and Migration: Some Findings}

In looking at the findings presented by statistics and surveys, we note, first, a very striking fact as far as the discourse on science in Europe is concerned: an enormous disparity between European countries regarding every aspect of mobility and migration in science. In some European countries, more than a quarter of the doctoral degrees are awarded to foreigners or foreign mobile persons, in others it is less than $5 \%$ or even less than $1 \%$. A survey undertaken by academics employed at institutions of higher education in more than ten European countries show that the proportions of those having been awarded the doctoral degree in another country ranges from $1 \%$ to $18 \%$, and, similarly, that the proportion of 'professional migrants', i.e. persons who have come to the country of current work at an earlier stage of their academic working life, varies between $1 \%$ and $11 \%$. At a time when many experts consider 'globalization' and 'knowledge society' as universal trends, key phenomena of a globalized society shaped by knowledge, i.e. the acquisition of international experience and the international mobility of the knowledge professions, are enormously uneven.

Disparities are even substantial in those areas in which we observe a long tradition of joint European policies to stimulate mobility and thereby to contribute to a more balanced situation all over the European Union or all over Europe. The most striking example is student mobility, where the ERASMUS programme of the European Union since 1987 and the "Bologna Process" under the joint responsibility of the national ministries in charge call for an increase, for more reciprocity and for a more balanced situation all over Europe. For example, the national ministers called in 2009 for a target to be reached by the year 2020 . By that time, $20 \%$ of students should have spent at least some period in another country during the course of study. When this target was adopted, the actual rate of the event of mobility in the course of study varied among European countries between less than $5 \%$ on the one hand and about $30 \%$ on the other. 
There are indications that these intra-European disparities are to some extent linked to differences of economic wealth and of the presumed quality of higher education and research between the various European countries. But other factors seem to play an enormous role as well. For example, the fact, that $18 \%$ of academics in Norway, but only $2 \%$ in Finland and $1 \%$ in the Netherlands have been awarded their doctoral degree in another country, cannot be attributed to differences of economic wealth and academic quality. The same holds true for the finding that about $30 \%$ of the students in Austria, but less than 5\% in the United Kingdom have spent some period of their study in another European country during the course of their study.

These differences between European countries are so striking in many instances, that one might challenge the value of any data presentation showing mobility and migration in Europe or about European country averages. In the light of this heterogeneity, Europe seems to be an artefact.

Second, the available quantitative information makes us aware of the enormous variety of modes of mobility in terms of length, purposes, career stages, etc. Even if attention is paid primarily to substantial cross-country moves, one might differentiate, as one of the comparative surveys suggests, between 'early immigrants', 'PhD immigrants', 'study mobile academics', 'PhD mobile academics' and 'professional migrants'. According to this study about one quarter of academics in Europe is mobile or migrating according to at least one of these categories. Another study, also paying attention to short encounters of mobility - for example a few months in another country during work on doctoral dissertation and stays abroad for short periods of research and teaching - comes to the conclusion that about two-thirds of researchers active in academia or in $\mathrm{R} \& \mathrm{D}$ holding a doctoral degree have had visible international experience and encounters within about a decade of their career after the award of the doctoral degree.

Third, we note some changes of mobility and migration as regards different dimensions that seems to be closely intertwined: a growth of

- small activities of mobility, such as teaching a course abroad or spending some time with research partners in other countries,

- mobility in the framework of cooperation and possibly partnerships,

- 'horizontal' mobility, i.e. to institutions and countries with similar quality of research as the institution and country of origin, and

- intra-European mobility.

On the basis of all the available quantitative sources, some experts point out that Europe primarily differs from other regions of the world in providing good opportunities for horizontal mobility and for frequent short-term mobility.

\section{Mobility and Migration in the Life of Individual Scholars}

Crossing borders for the purposes of study, of enhancing one's academic competences, of doing research and related work in other countries and of being in close touch with scholars all over the world tends to be viewed as valuable for the scientific 
world as a whole. There is hardly any comparable element in academia and the research system at large that is accompanied in the public discourse with so much and so unanimous praise.

It obviously makes sense for a student, a scholar in his or her formative years and for an experienced scholar not only to communicate and collect information across borders, but also to be physically mobile - be it for a short encounter, for a couple of months, for a period of one's educational or professional biography, or for a more or less permanent relocation. There is a range of typical rationales for mobility:

- climbing up the quality ladder (going to a place where academic quality is higher than at the place of origin),

- moving to a location where research in one's own area of expertise is strong,

- enhancing one's general abilities and reflective potentials through 'learning from contrast',

- improving one's inter-cultural competences,

- building up expert knowledge for those professions and related areas of research specialized on other cultures, societies and economies (such as Roman languages, Chinese studies, area studies) or on international interaction (e.g. international trade, international law),

- but also gaining from the symbolic value of internationality (having a $\mathrm{CV}$ with various international highlights).

Numerous studies have shown that some mobile students and scholars had one or two of these major rationales clearly in mind, but that many others considered a broad spectrum of rationales as important or were mobile without such a highly strategic agenda of their own - for example, because they were children of migrant parents, they crossed borders for family reasons, they enjoyed a change in life, or they just trusted that international experience might turn out to be valuable in one way or other. Moreover, there might have been other 'push' factors for mobility in play, such as poverty, wars or lack of academic freedom.

Various research projects have aimed at providing systematic evidence of the impact of international mobility on professional careers in general, on careers in the world of science, on international components of research, teaching and other areas of academic work, but also on general and professional satisfaction and on the internationality of life after having been mobile. By and large these projects confirm the conventional wisdom: those who had been mobile tend to be clearly more internationally active afterwards and many of them are professionally more successful in a broad range of professions and notably in academia and research.

But these studies call for more cautious and differentiated views. For example, data on the internationality of successful scholars (e.g. their prior mobility, their involvement in international projects or their co-publications with scholars from other parts of the world) often do not show the causal direction, i.e. the extent to which internationality caused the academic and research success or, in reverse, the extent to which success in academia and research caused increasing international 
visibility and consequently more mobility and other international activities. Moreover, research shows that many of those being internationally mobile as students or on early career stages are advantaged anyway in parental educational background, financial circumstances, academic achievement, etc; therefore, the correlation between mobility and subsequent career is to some extent 'spurious'.

Three additional phenomena are pointed out by systematic analyses on mobility in higher education and the world of science. The first is captured by the term 'migration'. This term addresses long-term or permanent moves across borders. Analyses in this domain of the actual policy discourse tend to concentrate on two extremes: the worldwide moves of the privileged, for example financial managers, consultants or others who live a cosmopolitan life on the one hand and those who are driven out of their home area due to wars, ecological catastrophes or poverty on the other hand. A close look at the world of science suggests that both ends of the spectrum are present: we note a top-class of cosmopolitan world-travelling scholars. And we observe a magnitude of scholars who more or less had been 'forced' ('pushed' might sound too mild) to leave their place of origin: Often attention is paid to the fortunate cases of upward mobility, and less often is attention paid to visible and not so visible long-term disadvantages and even discrimination.

The second additional phenomenon has already been mentioned above. It was known before systematic information was improved but has drawn less attention than it deserves: i.e. the extreme differences of international migration and mobility according to the country of origin. We might be interested in averages across countries (for example averages of all EU countries, all European countries, all economically advanced countries or all over the world) and estimate on the basis of the by no means perfect statistical data, for example, that more than $3 \%$ of higher education students in Europe study abroad in order to get a degree there, that almost $10 \%$ of European students have studied in another country for at least some time during the course of study, that about one fifth of those awarded a doctoral degree acquired it abroad, and that almost one tenth of scholars at higher education institutions in Europe had lived in another country before they started to study in higher education. But the differences by European country are certainly the most striking phenomenon. If we appreciate something in life such as owning a car, having a refrigerator at home, using the internet, or spending part of our holidays in another nice country, we note similar rates of 'consumption' in countries characterized by a similar level of wealth. But if it comes to international mobility in the world of science, we note enormous differences between European countries.

In trying to explain why actual mobility in science remains so uneven across European countries, although most studies show that mobility is highly appreciated and relevant for success in this domain, we note a variety of factors. As will be discussed below, policies in the different European countries vary substantially in the extent to which they encourage mobility of their own qualified learners and work force. Additionally, the actual career premium and the advantage of access to more interesting work in academia and research due to mobility is often small in Europe, where most mobility is not from deplorable to bright circumstances of scientific 
learning and work, but among environments of similar quality and where mobility has become so frequent that it is not anymore an exceptional feature of a CV. Thus, a representative survey, undertaken in 2012, of researchers in the more than 30 European countries participating in the major EU programmes of education and science shows that there are more researchers now who believe that mobility has negative career effects than those believing in the positive career effects.

Third, the available studies also show that high-quality research and career success in science does not consistently depend on mobility. Many scholars are internationally active in research collaborations or in joint publications without having been visibly mobile. Or many scholars opt for strong international approaches in research and possibly teaching without this being underpinned by extended academic experiences in other countries. As will be discussed below, we might come to the conclusion that both increasing mobility as well as opportunities of internationalization through other means, might challenge the distinctive value of mobility.

\section{The Roles Mobility and Migration Play for Countries and for Europe}

In the public discourse on the roles mobility and migration in science play for national and supra-national actors as well as for institutional actors, e.g. institutions of higher education and other institutions involved in research, we note references being made most often to 'countries'. This implies, first, that even under conditions of so-called 'globalization', the world of science is viewed as strongly shaped by nations and national interests and that we are not on the way towards a 'global village'; globalization does not seem to be linked predominantly with de-nationalization in science policy, but occasionally even with re-nationalization policy. Second, the 'country' is often depicted as a major actor without any specification of the role of 'government', 'market', institutions of higher education and research, professional associations, etc. Third, rivalry or 'competition' are viewed as the dominant rules of the game of international interaction where wins on the one side are linked to losses on the other side.

It is not customary anymore to talk about 'domination' or even 'imperialism' in science policy, but the narrative of 'brain drain' versus 'brain gain' has been and still is widespread. Of course, the rhetoric of 'competition' to 'attract talents' seems to be least controversial and most highly appreciated in those countries, where the winners or would-be winners of the international mobility and migration flows eventually reside. No matter what terms are appreciated - the underlying assumption is that 'vertical mobility' is the most salient feature of mobility, i.e. moves from countries of less favourable economic conditions and at most moderate potentials of research to those with a favourable research environment, and that the dominant host countries of mobility are the major winners, because they can 'cream off' the best talents among the inwards mobile students and scholars and thus contribute to the scientific progress of the host country. Moreover, these processes serve to reinforce respective reputation hierarchies of countries and strengthen the power of the host countries to influence the rules of the game in the scientific world. 
For some period, discussions focused on 'brain drain' versus ‘brain gain'. This met criticism as depicting worldwide migration and mobility in the world of science as a clear 'zero-sum game', where the losses for some countries equal the wins for the others and where countries with a dominant outwards mobility are the clear losers and those with a dominant inwards mobility are the clear winners. The term 'brain circulation', in contrast, was often employed in order to point out that countries with high rates of outwards mobility do not only 'lose', but also might experience some 'returns': some scholars might go back after a while to the country of origin and contribute to enhancement of research, international networking might be intensified as a side-effect of mobility, mobile professionals send back money to the country of origin, etc. Moreover, one could observe countries moving their position upwards in the international scientific reputation hierarchy, such as the Republic of Korea some time ago and China currently, and that some countries, such as Jordan, even pursue a policy of 'export' of qualified labour in order to enhance one's economic and scientific success. Altogether, this discussion on 'brain circulation' in fact has made clear that international mobility and migration is not completely a one-way and zero-sum game and that countries with a dominant outflow are not so much 'losers' as the migration and mobility statistics such might hint. Yet attention paid to the phenomenon of 'brain circulation' does not suggest that countries with high outflow rates of talented learners and scholars do not have to be concerned at all of experiencing any 'loss'. As long as not a real global vision substitutes nationalistic calculations, we will continue to note concern about 'losses' due to outwards mobility on the one hand, and on the other hand praise of the 'virtue' of 'competition' in 'attracting talents' without any serious concern about what that means for the other countries.

One could believe that 'Europe' is the main driver of trying to reach a 'brain gain' for all European countries, i.e. in mobilizing high inwards migration and mobility in science towards European countries. This might be assumed because the European Union - in the Lisbon Declaration of 2000 - opted for extremely instrumentalist jargon in advocating the establishment of a 'European Research Area' (ERA) by 2010 in order to create the 'most competitive economy' of the world. The policy, as often formulated, also aims at attracting an increasing number of talented persons from other parts of the world, who eventually opt for education, training and scholarly work in Europe. However, a look at the various 'progress reports' published by the European Commission on the implementation of the ERA shows that the issue of mobility of scholars and researchers is hardly treated. If at all, reference is made to student mobility, but the EU programmes support only a minority of the mobile students, and major European policies in favour of creating better conditions for student mobility are not coordinated in the framework of the European Union, but rather by the national ministers in charge of more than 40 European countries in the framework of the Bologna Process, and in this framework the ministers agreed after a long discussion in 2009 , that the priority target is to encourage one's own students' outwards mobility in order to enhance their competences through what might be called 'learning from contrast' - i.e. definitely not 'brain gain'.

Cooperation within the European Union is based on the objective of ensuring some kind of a balance between open competition for the success of the fittest on the 
one hand and social cohesion and efforts to keep inequalities within limits on the other hand. Many observers believe that the imbalances of intra-European mobility and migration in science tilt towards extreme inequality. In the past, the ERASMUS support for student mobility and Marie Curie support for young researchers were established as deliberate mechanisms of counterbalancing extreme unequal mobility streams. Now, the prevailing research promotion policies in the EU seem to be not only in favour of attracting 'top researchers from anywhere in the world', but also - according to many observers - to reinforcing intra-European competition in a way that inequalities of mobility and migration among scholars and scientists between European countries persist or even grow. The fear is widespread in Southern European countries as well as in Central and Eastern European countries, and this is fuelled by the current economic crisis, that the European science policy cares too much for the success of the fittest and not enough for cohesion and limitation of inequalities - among others as far as mobility and migration in science are concerned. According to many observers, substantial changes of research promotion in the EU are needed, e.g. making the European research 'periphery' more attractive, stimulating return flows, strengthening elements of cooperation across countries and other measures.

Obviously, the prevailing national sentiments and the dominant policies as regards migration and mobility in the world of science vary substantially between the European countries. Any careful analysis certainly would show that wishes to 'attract talents' and being a 'brain gain winner' are present everywhere, but only few countries seem to consider these as clear priorities - possibly combined with efforts to gain direct income through hosting and educating students and doctoral candidates. In many European countries, however, other objectives play an important role in the way of handling issues of mobility and migration in science: for example, a higher appreciation of academic dynamics than those of visible economic utility, a strong fostering of cross-country cooperation in research, a high regard for 'horizontal' mobility and migration as means of improving research, or a concern about the 'social cohesion' of the world, for example by providing substantial development aid to low-income and middle-income countries in the area of science. In many European countries we also observe widespread views that any support of mobility, migration and cooperation - without any highly targeted steering - might be beneficial eventually for the global world of science and its contribution to society.

\section{The Role Mobility and Migration Play for Institutions}

Over the years, discourses about science policies and strategies have paid increasing attention to the developments and strategies on the meso-level, i.e. institutions of higher education, research institutes and enterprises active in R\&D. Among other things, this reflects the fact that expenses for R\&D have increased in many countries more substantially than expenses for higher education and research at public institutions. In addition, institutions of higher education in many countries gained a higher room for manoeuvre as far as specific institutional strategies are concerned 
(often under the label of increasing 'autonomy'). Finally, the increasing popularity of 'rankings' of 'world-class universities' has reinforced a widespread notion within universities with highly respected quality of research, that they are 'competitors' on a world arena and that they must opt for institutional strategies that are promising for climbing a few ranks upwards in the global rankings of universities. Therefore, some analyses and policy debates as regards outwards mobility and incoming mobility to single universities and enterprises are similar with regard to 'brain gain', etc, to those regarding mobility flows from and to single countries.

Again, however, one might raise doubts that mobility and migration are primarily understood at meso-level with a view on 'brain gain' and income generation through hosting foreign students and doctoral candidates. Most of the international rankings do not include indicators of mobility. And international surveys show, for example, that the motives of universities for supporting mobility of students, doctoral candidates and scholars are quite varied and manifold. Thereby, altogether, 'cooperation' through 'exchange' and collaboration in research projects seems to play a more important role in most cases than 'competition'.

In sum, we note that both, national (and supra-national) as well as institutional policies and activities seem to be viewed, if we pay attention to the public 'noise', as increasingly embedded in worldwide rivalry as regards economic progress and societal well-being, whereby the world of science is seen as becoming a more important component and in this framework international mobility and migration are viewed as important components in the race for excellence and innovation. Concurrently however, we also note an increasing weight of other rationales, which are not put forward that noisily, but still strongly affect the world of science and within it mobility and migration. It is a matter of political taste or conviction which of these objectives and functions are believed to be more important.

\section{An Exaggerated Emphasis on Mobility and Migration within the Overall Efforts in Favour of Internationalization?}

In reflecting the role of migration and mobility in science, we might pay attention, at first glance, to the major moves in life and think of discoverers, emigrants or the medieval craftsmen who spent their early years of maturing wandering around. In fact, there are now - still minorities, but - sizeable numbers of persons who spend their study period, who work on a dissertation, do a post-doc, or spend a phase of their professional life as established scholars in another country, or that are migrants, i.e. having changed their domicile through their parents' move or having opted for permanent professional work in another country.

But a closer view draws our attention to the multitude of short mobility activities, and these do not seem to be less important by definition: numerous analyses suggest that a semester of study in another country, teaching of a single course in another country, or a research visit for a couple of weeks can have a salient impact. Moreover, small visits to other countries might add up to a chain of mobility events in the course of learning and work in science. 
But the majority spend such occasional short periods in another country that the term 'mobility' sounds like an exaggeration, e.g. a short visit of partners for a few days, a trip to an international conference, or even the so-called ERASMUS 'teaching staff mobility' might be named here, because most stays in another country for a short teaching activity in this framework do not last longer than a week.

In addition, academics and other researchers are increasingly involved in various modes of knowledge border-crossing that do not require physical mobility: altogether we observe increasing virtual communication and knowledge transfer, and the majority of scholars seem to be involved in international projects and correspondingly in activities such as co-publications with authors located in other countries. As regards students, we note substantial numbers of franchised study programmes, branch campuses and MOOCs (massive open online courses). Also, in various home programmes, international aspects are underscored as contributions to internationalization at home', and we observe that most academics report that international perspectives and approaches play a major role in their teaching and research activities. Finally, many students and scholars report that they have become internationally competent persons because life at home - inside and outside the world of science - has become international. Available information, thus, does not make clear whether there is a parallel trend of growth of physical mobility and other international activities or whether other international activities and experiences are substituting physical mobility.

Mobility and migration of individuals active in science is predominantly depicted as beneficial. This holds true, even though the losses, risks and failures on the part of the mobile persons cannot be ignored. But the narratives about the benefits remain quite diverse. In a simplified way, we can argue that the first narrative makes us believe that mobility and migration, as a rule, lead to a more international and a somewhat more successful career in science in general. According to the second narrative, scientific work is successful, if it is undertaken at a 'world-class' institution, a 'centre of excellence' or a 'knowledge hub'. The most privileged ones happen to be there, and the less privileged ones have to move there. According to the third narrative, purposes, modes and contexts of mobility and other means of international communication and cooperation are so manifold and so widespread that they have become part of life in science and are not linked to privileges anymore. Finally, a fourth narrative might be named: substantial first-hand international experience continues to be the major source of fostering competences that might be summarized under the label 'international understanding'.

Altogether, migration and mobility are likely to be more often beneficial than disadvantageous for the individual academic and researcher. This does not preclude, however, options of close affiliation with the nation, region and locality, avoidance of mobility for the sake of stable family life or various other reasons not to opt for extended mobility or migration. There might also remain in the future a relatively open choice between a mobile career, like that of Erasmus, and a non-mobile career, like that of Immanuel Kant. 


\section{Conclusion}

Migration and mobility in science is a theme that deserves attention, first, because we encounter an enormously complex setting. One cannot stick to simple statistics of frequencies and rates of foreign scholars within an institution or a country or of rates of persons currently staying in another country for study, work on doctoral dissertation or in the framework of a post-doctoral fellowship. Mobility might stretch from short visits to perennial globetrotting, and migration might range from parents' emigration to permanent change of professional settlement. Information in this domain is most interesting if it touches upon the causes for moves, the experiences in other countries, and the impact of mobility and migration - for the individual, the affected institutions as well as for the countries and regions.

A look at the role migration and mobility play for the individual clearly suggests that border-crossing in the course of the formation of competences and the course of academic or other research tends to be beneficial for career success, research work and inter-cultural understanding. One should not overlook, however, that many mobile researchers consider the 'costs' higher than the 'benefits' and that other life options than that of a peripatetic life are often preferred and feasible in the $21 \mathrm{st}$ century. Moreover, one might ask whether major physical mobility will go on increasing or whether the multiple ways of short border-crossing activities and virtual border-crossing might substitute physical mobility to some extent.

Consideration of the role mobility plays for institutions and countries tends to be easily captured by the Zeitgeist of discourse: by attention paid to mobility in terms of a 'war for talents', i.e. the enormous efforts made to increase 'brain gain'. We note, however, that the policies of the various European countries and the strategies of the various universities, research institutes and other institutions active in R\&D are manifold. There is also appreciation of horizontal mobility and enhancing intercultural understanding with the help of mobility. Mobility is viewed as having worth with regards the substance of knowledge and work, and readiness exists to favour modes of mobility and cooperation that help to reduce worldwide inequality.

In Europe, we observe enormous disparities of intra-European mobility which altogether could be described as a 'brain gain' for the economically most successful regions of Europe and as a 'brain drain' for the peripheries of Southern as well as Central and Eastern Europe. This suggests that European science policies do not seriously aim at or certainly are not successful in striking a balance between stimulating the potentials of market steering on the one hand and in fostering cohesion across Europe and in keeping inequalities between European countries within limits on the other hand. New science policies seem to be needed that really could be viewed as 'European policies'.

\section{About the Authors}

Alessandro Cavalli is emeritus professor of sociology at the University of Pavia, president of CIRSIS (Center for Research on Higher Education Systems) of the same 
university, president of the Scientific Council of IARD Institute, and member of the Council of Fondazione per la Scuola. His main interests focus on the history of social thought between the 19th and 20th centuries, collective memory, youth and education. He has been a member of several evaluation committees in Belgium, Germany, Italy and Portugal. He is editor of Mundus, a journal on history teaching. Recent publications include Giovani a scuola (Young People at School), with G. Argentin, Il Mulino, Bologna 2007. Deux Pays, deux Jeunesses? (Two countries, two Youths?), with V. Cicchelli, O. Galland, Presses Universitaires de Rennes, 2008.

Ulrich Teichler was professor at the International Centre for Higher Education Research (INCHER-Kassel), University of Kassel (Germany) from 1978 to 2013, and he served for 16 years as the Centre's Director. He studied sociology, earned his Dr. phil. with a dissertation on higher education in Japan, and spent his junior career at the Max Planck Institute for Educational Research, Berlin. He has had extended research periods in Japan and the Netherlands, was visiting professor or had other teaching arrangements in nine countries, including at Northwestern University (USA) and College of Europe (Belgium), and has had academic visits to more than 80 countries. His major research areas are higher education and the world of work, comparison of higher education systems, international mobility in higher education, and the academic profession. He has authored more than 1000 publications. Honours include many years of chairmanship of the Consortium of Higher Education Researchers (CHER), membership and key functions in the Academia Europaea and the International Academy of Education, the Comenius Prize of UNESCO and the Dr. h.c. of the University of Turku (Finland). 